\title{
Inhibition of Bcl6b promotes gastric cancer by amplifying inflammation in mice
}

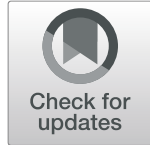

\author{
Wang-Yu Cai ${ }^{1,4^{*}+} \mathbb{D}$, Ling-Yun Lin ${ }^{1,4 \dagger}$, Lin Wang ${ }^{1,24^{*}+}$, Li Yang ${ }^{4 \dagger}$, Guo-Dong Ye $e^{3,5}$, Qiang Zeng ${ }^{1,4}$, Jia Cheng ${ }^{1,4}$, \\ Yuan-Yuan Xie ${ }^{1,4}$, Mao-Li Chen ${ }^{6}$ and Qi-Cong Luo $34^{3 *}$
}

\begin{abstract}
Background: Chronic gastritis has been demonstrated to be a key cause of gastric cancer (GC), and control of gastric inflammation is regarded as an effective treatment for the clinical prevention of gastric carcinogenesis. However, there remains an unmet need to identify the dominant regulators of gastric oncogenesis-associated inflammation in vivo.
\end{abstract}

Methods: The mouse model for the study of inflammation-associated GC was induced by Benzo[a]pyrene (BaP) intragastric administration in Bcl6b $b^{-1-}$ and wildtype mice on a C57BL/6 background. 5-Aza-2'-deoxycytidine (5-Aza), the demethylation drug, was intraperitoneally injected to restore Bcl6b expression. Human GC tissue array was used to analyse patient survival based on BCL6B and CD3 protein expression.

Results: Bcl6b was gradually downregulated by its own promoter hypermethylation in parallel to an increasing inflammatory response during the progression of BaP-induced gastric carcinogenesis in mice. Moreover, knockout of Bcl6b dramatically worsened the severity of gastric cancer and aggravated the inflammatory response in the BaPinduced mice GC model. Re-activation of Bcl6b by 5-Aza impeded inflammatory amplification and BaP-induced GC development, prolonging survival time in wildtype mice, whereas no notable curative effect occurred in $B c / 6 b^{-1-}$ mice with 5-Aza treatment. Finally, significant negative correlations were detected between the mRNA levels of BCL6B and inflammatory cytokines in human GC tissues; patients harbouring BCL6B-negetive and severeinflammation GC tumours were found to exhibit the shortest survival time.

Conclusions: Epigenetic inactivation of Bcl6b promotes gastric cancer through amplification of the gastric inflammatory response in vivo and offers a new approach for GC treatment and regenerative medicine.

Keywords: Gastric cancer, Bcl6b, Mouse gastric cancer model, Inflammation, 5-Aza therapy

\section{Background}

As the fifth-most commonly diagnosed cancer and the third leading cause of cancer-related death, gastric cancer (GC) remains an important cancer worldwide. In particular, Asia is responsible for the largest GC incidence and mortality [1]. Chronic gastritis, the persistent

\footnotetext{
* Correspondence:

wangyu_cai@hotmail.com; wanglin_linda82@163.com; qcluo@xmu.edu.cn 'Wang-Yu Cai, Ling-Yun Lin, Lin Wang and Li Yang contributed equally to this work.

'Department of Gastrointestinal Surgery, Zhongshan Hospital, Xiamen University, No. 201-209 Hubinnan Road, Xiamen 361004, Fujian Province, China

${ }^{3}$ Laboratory of Xiamen Cancer Hospital, The First Affiliated Hospital of Xiamen University, No.55 Zhenhai Road, Xiamen 361003, Fujian Province, China

Full list of author information is available at the end of the article
}

inflammation of the gastric mucosa, is a well-identified cause of GC [2]. Currently, the effective control of gastric mucosal inflammation has highlighted the importance of GC inhibition [3].

H. pylori infection and carcinogenic intake are key risk factors of inflammation associated gastric oncogenesis [4-6]. During chronic inflammation, the pronounced release of cytokines and chemokines, including interleukin1 beta (IL-1 $\beta$ ), tumour necrosis factor alpha (TNF- $\alpha$ ), interleukin-8 (IL-8), and interleukin-6 (IL-6) [7, 8], drive the infiltration of neutrophils, macrophages and $\mathrm{CD}^{+} \mathrm{T}$ cell into the gastric mucosa [9]. Despite the well-known causal relationship between chronic gastritis and GC [10], the key regulators of gastric oncogenesis-associated inflammation have not been completely defined.

(C) The Author(s). 2019 Open Access This article is distributed under the terms of the Creative Commons Attribution 4.0 International License (http://creativecommons.org/licenses/by/4.0/), which permits unrestricted use, distribution, and reproduction in any medium, provided you give appropriate credit to the original author(s) and the source, provide a link to the Creative Commons license, and indicate if changes were made. The Creative Commons Public Domain Dedication waiver (http://creativecommons.org/publicdomain/zero/1.0/) applies to the data made available in this article, unless otherwise stated. 
B-cell CLL/lymphoma 6 member B (BCL6B), also known as $B A Z F$, is a homologue of the human protooncogene B-cell CLL/lymphoma 6 (BCL6) [11]. BCL6B has a $94 \%$ identical amino acid sequence at the zinc finger motifs and a $65 \%$ identical $\mathrm{BTB} / \mathrm{POZ}$ domain to BCL6, thus, they bind to similar target DNA sequences to act as transcriptional repressors. However, the tissue expression pattern and pathological function of BCL6B differ from that of BCL6 [12-14]. In recent studies, BCL6B has been identified as a novel tumour suppressor, which is silenced or downregulated by promoter hypermethylation and is associated with poor survival in colorectal carcinoma [15], hepatocellular carcinoma $[16,17]$ and GC [18-20]. In terms of a molecular mechanism, several lines of evidence have revealed that BCL6B interacts with the Notch, STAT, p53 and PI3K/AKT signalling pathways, all of which may be involved in inflammatory response regulation in cancer cells $[15,16,21,22]$. In vivo, Bcl6b inhibits hepatocellular inflammation to obstruct liver damage and fibrogenic induction in liver-specific Bcl6b transgenic rats [23]. However, whether BCL6B functions as a key tumour suppressor and inflammatory regulator during the progression of gastric oncogenesis in vivo requires further study.

In order to investigate the role of $\mathrm{Bcl6b}$ in gastric tumourigenesis, we assessed Bcl6b expression and the degree of inflammation during the progression of Benzo[a]pyrene (BaP)-induced gastric carcinogenesis in mice. Based on this established mouse GC model, we induced gastric tumours within wildtype and $B c l 6 b^{-1-}$ mice, and then treated with or without the demethylation drug 5-Aza-2'-deoxycytidine (5-Aza) to induce Bcl6b reactivation. We found that eradication of Bcl6b promoted gastric carcinogenesis by amplifying inflammation in mice and that BCL6B was associated with inflammation and survival in GC patients and mice. These results highlight the role of BCL6B in the modulation of malignant GC phenotypes in vivo and provide a potential target to develop a new therapeutic strategy for gastric cancer treatment.

\section{Methods}

\section{Animals and treatments}

$\mathrm{Bcl}^{-1-} \mathrm{b}^{-1}$ mice on a C57BL/6 background were bred by Cyagen (Guangzhou, China). C57BL/6 mice were obtained from the Xiamen University Laboratory Animal Centre (Xiamen University, Xiamen, China). Mice had access to a standard chow diet and water ad libitum and were caged in a pathogen-free environment. All mice in our experiments were gender and age matched. BaP (Sigma-Aldrich, St Louis, MO, USA) was freshly prepared in sunflower oil (Sigma-Aldrich, St Louis, MO, USA) at a concentration of $5 \mathrm{mg} / \mathrm{ml}$. At postnatal day
40-45 (P40-45), mice were treated with intragastric administration of $0.01 \mathrm{ml} / \mathrm{g}$ body weight $\mathrm{BaP}$ two times weekly for five weeks. The first intragastric dose was at week 0 . Mice were randomized to receive either an intraperitoneal injection of 5 -Aza $(0.5 \mathrm{mg} / \mathrm{kg}$ body weight, twice a week; Sigma-Aldrich, St Louis, MO, USA) or saline during week $10-25$ for 15 weeks. Mice were euthanized, and stomach tissues were collected for examination at specific times. All mice were used in accordance with the guidelines of the Institutional Animal Care and Use Committee of the Xiamen University Laboratory Animal Centre.

\section{RNA extraction and quantitative PCR analysis}

Total RNA from mouse tissues was extracted using TRIzol (cat. no.: 15596026, Invitrogen, Thermo Fisher Scientific, MA, USA) and was quantified via NanoDrop (Thermo Fisher Scientific, MA, USA). Equal amounts of RNA were reverse-transcribed with the HiFi-MMLV cDNA Kit from CWBIO (cat. no.: CW0744, CoWin Biotech, Beijing, China) to produce cDNA according to the manufacturer's protocol. Quantitative PCR (qPCR) was performed using a CFX96 Touch Real-Time PCR Detection System (Bio-Rad, CA, USA) with the UltraSYBR Mixture from CWBIO (cat. no.: CW0956, Beijing CoWin Biotech, Beijing, China) according to the manufacturer's protocol. The expression levels were quantified using the $2^{-\Delta \Delta \mathrm{Ct}}$ (where $\mathrm{Ct}$ is the threshold cycle) method. Eukaryotic 18S rRNA endogenous control was used as an internal standard. The following primer sequences for quantitative PCR were used:

18S: 5' - GTCTGTGATGCCCTTAGATG - 3' (forward), 5' - AGCTTATGACCCGCACTTAC - 3' (reverse);

hTNF- $\alpha$ : 5' - AGCCTGTAGCCCATGTTGTAGC - 3' (forward),

5' - CCTTGGCCCTTGAAGAGGAC - 3' (reverse);

hIL-8: 5' - TTGGCAGCCTTCCTGATTTCT - 3' (forward),

5' - GGTCCACTCTCAATCACTCTCA - 3' (reverse);

hIL-1 $\beta$ : 5' - GAGCTCGCCAGTGAAATGATG - 3' (forward),

5' - TCGGAGATTCGTAGCTGGATG - 3' (reverse);

hBCL6B: 5' - CTACGTCCGCGAGTTCACTC - 3'

(forward),

5' - CCCGGAAAATTGAATAGAAG - 3' (reverse); mTNF- $\alpha$ : 5' - TGACAAGCCTGTAGCCCACG - 3' (forward),

5' - GGCAGCCTTGTCCCTTGAA - 3' (reverse); mIL-8: 5' - CAAGGCTGGTCCATGCTCC - 3' (forward), 5' - TGCTATCACTTCCTTTCTGTTGC - 3' (reverse); mIL-1 1 : 5' - GAAATGCCACCTTTTGACAGTG - 3' (forward), 5' - TGTTGATGTGCTGCTGCGAG - 3' (reverse); 
mBcl6b: 5'- TCCTCCGACGTGCTTAGCAAT - 3' (forward),

$$
\text { 5' - GGCCCCGGAAAATTGAATAGA - 3' (reverse). }
$$

\section{Enzyme-linked immunosorbent assay}

Mouse serum levels of TNF- $\alpha$ and IL-1 $\beta$ were assessed and quantified using enzyme-linked immunosorbent assay (ELISA) kits (TNF- $\alpha$ : cat. no.: MTA00B, R\&D systems, Minneapolis, USA; IL-1 $\beta$ : cat. no.: 88-7013-22, Thermo Fisher Scientific, MA, USA) according to the manufacturers' protocol. Enzyme concentration was quantified by measuring the optical density at a wavelength of $450 \mathrm{~nm}$ (OD450) using a spectrophotometer (Thermo Fisher Scientific, MA, USA).

\section{Western blotting}

Mouse tissues were lysed with SDS lysis buffer. AntimBcl6b (cat. no.: ab87228, Abcam, Cambridge, MA, USA) and anti- $\beta$-actin (cat. no.: A1978, Sigma-Aldrich, Darmstadt, Germany) were used for immunoblotting. $\beta$ Actin was used as an internal control.

\section{Morphological observation}

The stomach of the mice was cut off from the greater curvature and placed on a stereomicroscope. Turn on the bottom light source, count and measure tumour nodules larger than $0.5 \mathrm{~mm}$ in diameter according to the lens scale. The average number of tumour nodules per tumour bearing mouse was calculated as tumour number. The average maximal diameter of tumour nodule per tumour bearing mouse was calculated as max size. Tumour incidence was the number of mice carrying at least 1 tumour nodule expressed as percentage incidence. Meanwhile, H\&E staining and Pan-Cytokeratin immunostaining in the gastric tissue of mice were further used for qualitative analysis of gastric tumours.

\section{H\&E staining}

For histologic analysis, mouse tissues were fixed with $10 \%$ neutral buffered formalin overnight, embedded in paraffin, and cut into $4.5 \mu \mathrm{m}$ sections using a microtome (Leica RM2235; Leica Microsystems). After dewaxing and rehydration, the sections were stained in haematoxylin solution (cat. no.: D006, Nanjing Jiancheng Bioengineering Institute, Nanjing, China) for $3 \mathrm{~min}$, washed in running tap water and then differentiated in $1 \%$ acid alcohol for $30 \mathrm{~s}$, followed by counterstaining with eosin (cat. no.: D006, Nanjing Jiancheng Bioengineering Institute, Nanjing, China) for $30 \mathrm{~s}$. Gastric tumours were identified and quantified on sections.

\section{Immunohistochemistry}

All tissues were fixed in 10\% neutral buffered formalin, paraffin embedded, and sectioned. After dewaxing and rehydration, antigen retrieval was performed by boiling in citrate buffer ( $\mathrm{pH}$ 6.0) for $20 \mathrm{~min}$. Immunostaining was performed using the Maxim UltraSensitive SAP Kit (cat. no.: Kit9710, Maxim Biological Technology, Fuzhou, China). Sections were pre-treated with peroxidase blocking buffer for $10 \mathrm{~min}$ at room temperature. After treatment with blocking buffer (5\% normal goat serum in PBS) for 10 min at room temperature, sections were incubated with anti- hBCL6B (1:500 dilution; cat. no.: ab180084, Abcam, Cambridge, MA, USA), antimBcl6b (1:500 dilution; cat. no.: ab87228, Abcam, Cambridge, MA, USA), anti-CD3 (1:300 dilution; cat. no.: sc-20047, Santa Cruz Biotechnology, Texas, USA), anti-Ki-67 (cat. no.: 790-4276, Ventana Medical systems, AZ, USA), or anti- Pan-Cytokeratin (cat. no.: IHCMO67, Guangzhou ambip pharmaceutical technology, Guangzhou, China) in blocking buffer. Sections were then incubated with a secondary antibody followed by 3 , 3 '-diaminobenzidine (DAB) staining with a DAB kit (cat. no.: DAB2031, Maxim Biological Technology, Fuzhou, China). Images were obtained using a computerized imaging system (Leica Microsystems, Imaging Solutions Ltd., Cambridge, UK). Identical settings were used for each photograph using Leica QWin Plus v3 software. To strengthen our main conclusion and further investigate the clinical significance of BCL6B and CD3 in GC, we performed tissue microarray analysis and classified all tumours that presented with more than $5 \%$ of cells over the threshold as BCL6B or CD3 positive.

\section{Bisulphite sequencing PCR}

DNA purified from mouse tissues was subjected to bisulphite sequencing PCR using a DNA Methylation Kit (cat. no.: CW2140, Beijing CWbio Biotech, Beijing, China) following the manufacturer's instructions. PCR primers were designed targeting the $\mathrm{CpG}$ sites of the mouse Bcl6b gene (starting 80-bp upstream of the mouse Bcl6b transcription start site (TSS) and ending 100-bp downstream of the TSS):

5' - GGGTTTATTATTTGGAGAGT - 3' (forward), 5' - TTAATTCTTACCCCTATCCC - 3' (reverse).

\section{Human gastric cancer samples}

Tissue microarrays from 186 GC patients (HStmA180Su09/ HStmA180Su13) and cDNA microarrays from $45 \mathrm{GC}$ patients (cDNA-HStmA030CS01/ cDNA-HStmA060CS01) were purchased from Shanghai Outdo Biotech Co., Ltd. (Shanghai, China). The studies were conducted in accordance with the International Ethical Guidelines for Biomedical Research Involving Human Subjects (CIOMS), and the research protocols were approved by the Clinical Research Ethics Committee of Zhongshan Hospital of Xiamen University. 


\section{Statistical analysis}

Statistical analyses were performed with GraphPad Prism 6.0. Data are presented as the mean \pm SD. The significance of the mean values between two groups was analysed by Student's $t$ test. Pearson correlation analysis was performed to determine the correlation between two variables. Survival analysis was performed using a logrank test. $P<0.05$ was considered statistically significant.

\section{Results}

The expression patterns of Bcl6b and inflammatory factors correlated with the progression of BaP-induced gastric carcinogenesis

To elucidate whether $\mathrm{Bcl} 6 \mathrm{~b}$ is regulated in $\mathrm{BaP}$-induced gastric carcinogenesis in vivo, a mouse gastric cancer model was established in $\mathrm{P} 40-45 \mathrm{C} 57 \mathrm{BL} / 6$ mice by intragastric administration of $\mathrm{BaP}(0.05 \mathrm{mg} / \mathrm{g})$ twice weekly for five weeks. Throughout the progression of BaP-induced gastric carcinogenesis, gradual pathologic alterations and eventual tumour granules were monitored by $H \& E$ staining of mouse stomach tissues (Fig. 1a). Simultaneously, the expression of Ki-67, a general proliferation marker that can be used to characterize gastric tumourigenesis, was dramatically elevated throughout this progression (Fig. 1a). Bcl6b protein expression in mouse gastric mucosa was detected by immunostaining and gradually decreased during gastric carcinogenesis (Fig. 1a). Furthermore, quantitative PCR (qPCR) revealed a similar trend towards downregulated expression of Bcl6b messenger RNA (mRNA) throughout this process (Fig. 1b). Since $B C L 6 B$ has been reported to be silenced via its promoter hypermethylation in human gastric cancer [19], bisulphite genomic sequencing (BGS) analysis was performed, which subsequently revealed that the methylation status of the $B c l 6 b$ promoter was elevated during BaP-induced gastric carcinogenesis (Fig. 1c). We next investigated whether BaP-induced gastric carcinogenesis was accompanied by an elevated inflammatory response. Quantitative analysis of the mRNA levels of TNF- $\alpha$, IL- $1 \beta$ and IL- 8 in gastric mucosal tissues showed that the inflammatory response was significantly activated in parallel with tumourigenesis (Fig. 1d). TNF- $\alpha$ and IL-8 protein levels in mouse serum as detected by ELISA also displayed a gradually increasing trend during $\mathrm{BaP}$ induction (Fig. 1e). Taken together, the above results suggest that Bcl6b was downregulated by promoter methylation along with activated inflammation in BaP-induced mouse gastric cancer model.

\section{Eradication of Bcl6b aggravates gastric tumourigenesis and amplifies inflammation in BaP-treated mice}

To elucidate whether Bcl6b has any effect on inflammation associated gastric tumourigenesis in vivo, BaP-induced mouse gastric cancer models were established in $\mathrm{Bcl}_{6} \mathrm{~b}^{-/-}$ and wildtype mice. We then sacrificed the mice and identified and quantified the gastric tumour load at 27 weeks after the initial intragastric $\mathrm{BaP}$ administration. Bcl6b expression in the gastric mucosa as detected by immunostaining were eradicated thoroughly within $B c l 6 b^{-1-}$ mice, and trace Bcl6b was expressed in wildtype mice upon $\mathrm{BaP}$ treatment (Fig. 2a, right). Images of gross gastric morphology (Fig. 2a, left), H\&E staining (Fig. 2A, middle) and Pan-Cytokeratin immunostaining (Additional file 1: Figure S1) showed that tumour number (Fig. 2b) and maximum size (Fig. 2c) were significantly higher in Bap-treated $B c l 6 b^{-/-}$mice versus the control group. A greater than $30 \%$ increase in the incidence of tumour development upon $\mathrm{BaP}$ treatment was also observed in $\mathrm{Bcl}_{6} \mathrm{~b}^{-/-}$mice (Fig. 2d). Moreover, we evaluated the number of Ki-67 immunopositive cells in the gastric mucosa of BaP-treated mice; $B c l 6 b^{-1-}$ mice exhibited a dramatic 2-fold increase in Ki-67 labelling relative to control mice (Fig. 2e). Thus, these results indicate that eradication of Bcl6b aggravates BaP-induced gastric tumourigenesis in vivo.

Given that upregulated gastric inflammatory cytokines, such as TNF- $\alpha$, IL- $1 \beta$ and IL- 8 increase the risk of GC [7, 24], we next investigated whether GC-sensitive $\mathrm{Bcl} \mathrm{bb}^{-1-}$ mice had increased levels of inflammatory factors upon $\mathrm{BaP}$ treatment. Compared to control mice, the mRNA levels of inflammatory cytokines TNF- $\alpha$, IL$1 \beta$ and IL- 8 in the gastric mucosa were dramatically elevated in BaP-treated $B c l 6 b^{-1-}$ mice (Fig. 3a). Additionally, ELISA revealed that TNF- $\alpha$ and IL- $1 \beta$ serum protein levels were also significantly increased in BaP-treated $\mathrm{Bcl} \mathrm{bb}^{-1-}$ mice (Fig. 3b). Since inflammatory cytokines drive CD3-positive inflammatory T-cell infiltration into the gastric mucosa during gastric carcinogenesis, we next evaluated the number of CD3 immunopositive cells in the gastric mucosa of BaPtreated mice. As expected, BaP-treated $\mathrm{Bcl} 6 \mathrm{~b}^{-1-}$ mice exhibited a dramatic 2-fold increase in CD3 labelling relative to control mice (Fig. 3c). Taken together, these data suggest that the inflammatory response is amplified by Bcl6b ablation, which may aggravate BaP-induced gastric carcinogenesis in vivo.

\section{5-Aza re-activates Bcl6b and attenuates the inflammatory response in BaP-treated mice}

As Bcl6b was dramatically downregulated by promoter methylation in our BaP-induced mouse gastric cancer model, we therefore hypothesized that the demethylation drug 5-Aza may ameliorate the BaP-induced inflammatory response during gastric carcinogenesis through reactivated Bcl6b. To test this hypothesis, P40-45 C57BL/ $6 \mathrm{Bcl} \mathrm{b}^{-1-}$ and wildtype mice were given $\mathrm{BaP}$ to induce gastric cancer as before during week $10-25$ with or 


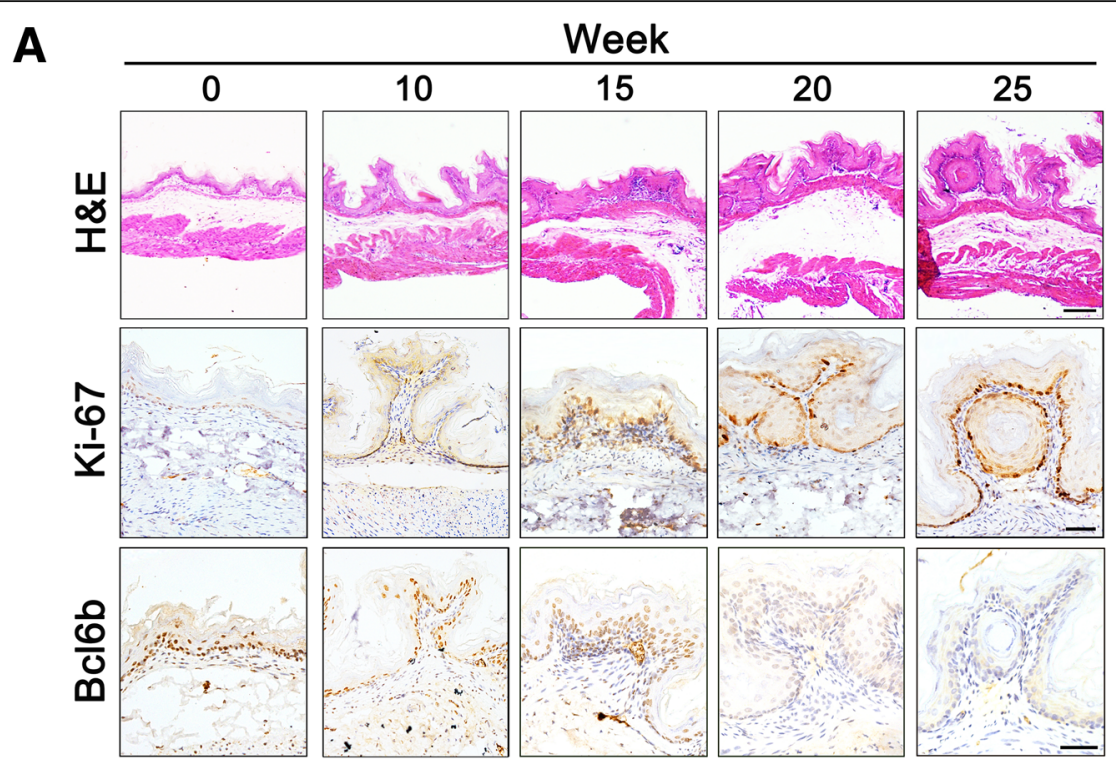

B
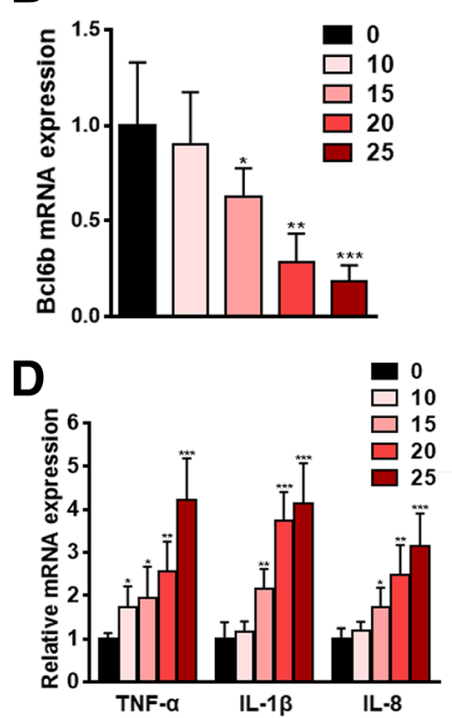

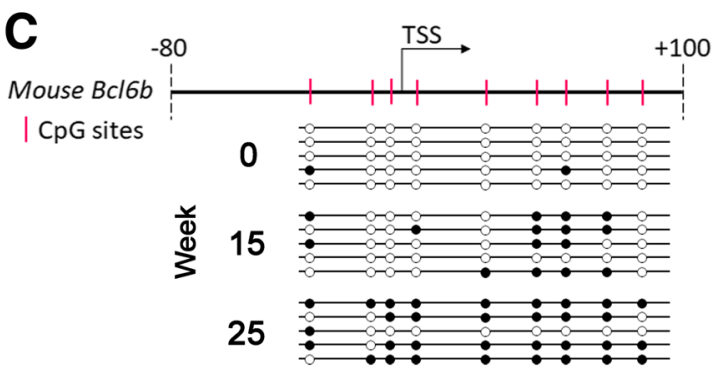

$\mathbf{E}$

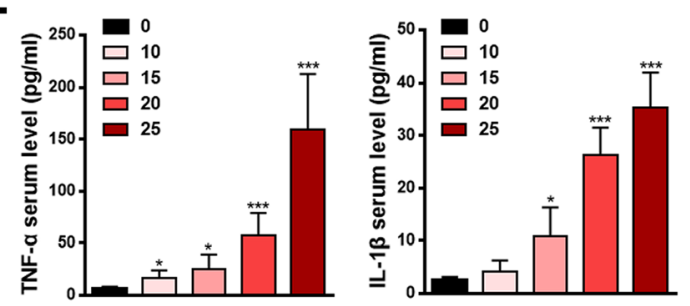

Fig. 1 Bcl6b was downregulated by promoter methylation along with activated inflammation throughout the progression of BaP-induced gastric carcinogenesis in mice. (a) Representative images showing H\&E staining of stomachs (Scale bar, $100 \mu \mathrm{m}$ ) and immunostaining of Ki-67 and Bcl6b expression in mouse gastric samples (Scale bar, $50 \mu \mathrm{m}$ ) throughout the progression of BaP-induced carcinogenesis. (b) qRT-PCR revealed Bcl6b mRNA levels in mouse gastric samples during the progression of BaP-induced carcinogenesis. (c) A typical CpG island spans the promoter region of mouse Bcl6b. Each vertical bar represents a single CpG site. The transcription start site (TSS) is indicated by a curved arrow. Bisulphite genomic sequencing (BGS) analysis revealed the methylation status of $B c / 6 b$ in mouse gastric samples during the progression of BaP-induced carcinogenesis. Filled circles: methylated CpG sites; open circles: unmethylated CpG sites. (d, e) qRT-PCR revealed the TNF-a, $I L-1 \beta$ and IL-8 mRNA levels in mouse gastric samples (D) and ELISA revealed the serum protein levels of TNF-a and IL-1 3 (e) during the progression of BaP-induced gastric cancer in mice. Data are presented as the mean \pm SD; $n=5$ per group. ${ }^{*} P<0.05 ;{ }^{* *} P<0.01$; ${ }^{* * *} P<0.001$; unpaired two-tailed Student's $t$ tests

without the demethylation drug 5-Aza at a dose of 0.5 $\mathrm{mg} / \mathrm{kg}$ for 15 consecutive weeks (Fig. 4a). Mice were euthanized, and stomach tissues were collected for examination at the end of 5-Aza treatment at week 25 . As expected, Western blot and immunostaining results showed that Bcl6b protein expression was remarkably re-activated upon 5-Aza treatment in the gastric mucosa of the wildtype group, while 5-Aza treatment had no effect on Bcl6b activation in the Bcl6b $b^{-1-}$ mice (Fig. 4b). Next, gastric mucosal Inflammatory cytokines such as TNF- $\alpha$, IL- $1 \beta$ and IL- 8 were evaluated by qPCR and showed significantly lower expression in 5-Aza-treated wildtype mice compared to saline controls, while 5-Aza had only a minor effect in $B c l 6 b^{-/-}$mice (Fig. 4d). 

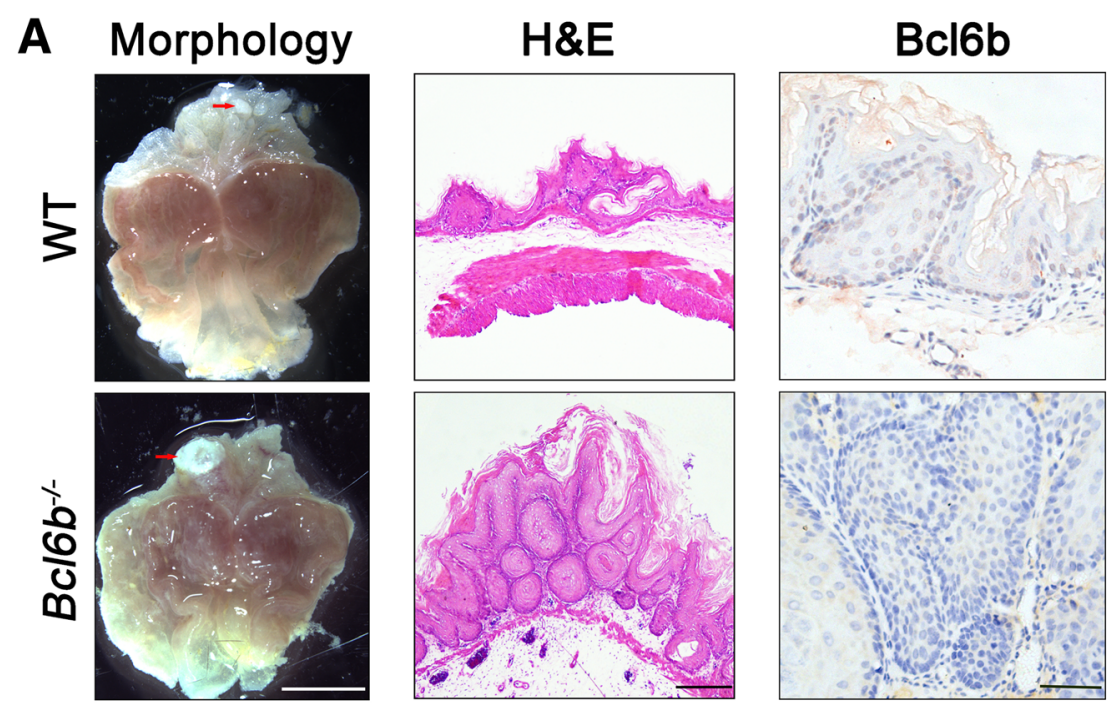

B

C
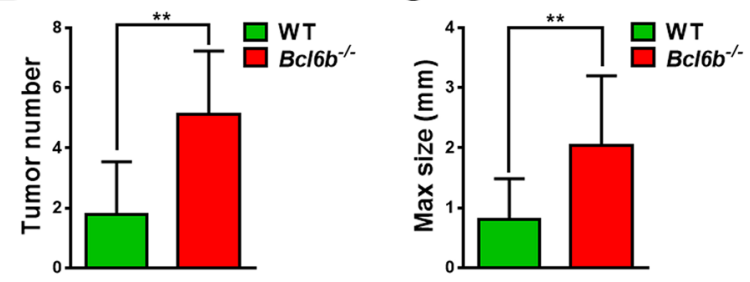

D

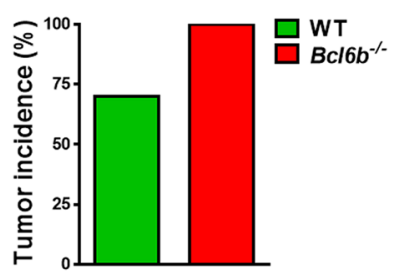

E

WT

$\mathrm{Bcl} 6 \mathrm{~b}^{-1-}$
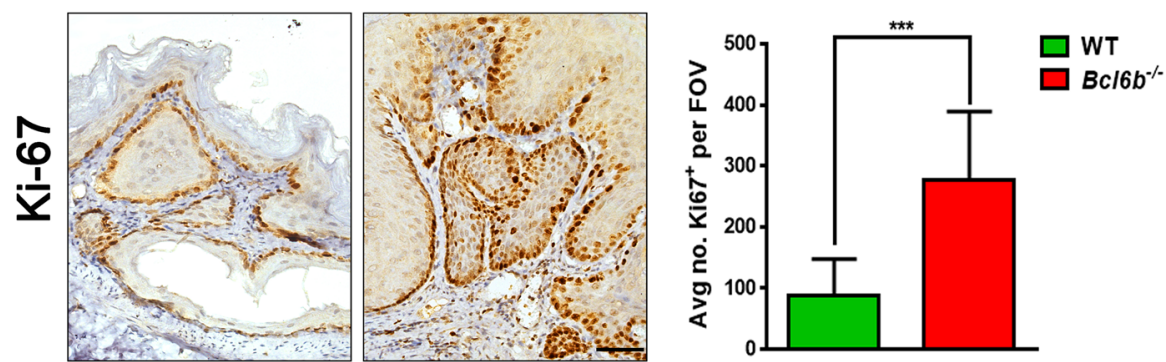

Fig. $2 \mathrm{Bcl6b}^{-1-}$ mice developed more gastric tumours following BaP treatment. (a) Representative images showing gross morphology (Scale bar, $5 \mathrm{~mm}$ ), H\&E staining (Scale bar, $100 \mu \mathrm{m}$ ) and immunostaining of Bcl6b expression (Scale bar, $50 \mu \mathrm{m}$ ) from stomachs harbouring BaP-induced tumours (27 week) from Bcl6b $b^{-1-}$ mice and WT controls. The gastric tumour granules were indicated by red arrows. (b-d) Tumour number (b), maximal size (c), and tumour incidence (d) in the stomachs of WT and $B c / 6 b^{-1-}$ mice after intragastric administration of BaP (27 week). (e) Representative images and quantification of Ki-67-immunopositive cells in Bap-induced gastric tumours (27 week) from Bcl6b ${ }^{-/-}$mice and WT controls. Scale bar, $50 \mu \mathrm{m}$. Data are presented as the mean \pm SD; $n=10$ per group. ${ }^{* *} P<0.01 ;{ }^{* *} P<0.001$; unpaired two-tailed Student's $t$ tests

Similar results were achieved when we performed ELISA to detect serum protein levels of TNF- $\alpha$ and IL-1 $\beta$ (Fig. 4e). In addition, $\mathrm{CD}^{+}$inflammatory $\mathrm{T}$ cells were found to be reduced by $75 \%$ in the above Bcl6b-re-activated wildtype group compared to saline controls, whereas no significant change in the $\mathrm{Bcl}_{6 b^{-1-}}$ mice was observed (Fig. 4c). Therefore, these results suggest that 5 -Aza can inhibit BaP-induced gastric inflammation dependent on Bcl6b re-activation in vivo.
5-Aza ameliorates BaP-induced gastric oncogenesis depended on Bcl6b in vivo

To further address whether 5-Aza has any beneficial effects on GC formation, we identified and quantified the gastric tumour load in BaP-treated $\mathrm{Bcl}_{6} \mathrm{~b}^{-1-}$ mice and wildtype controls with or without 5-Aza treatment. As indicated by morphologic images (Fig. 5a), H\&E staining (Fig. 5b) and Pan-Cytokeratin immunostaining (Additional file 2: Figure S2), the demethylation drug 5-Aza obviously decreased tumour number 

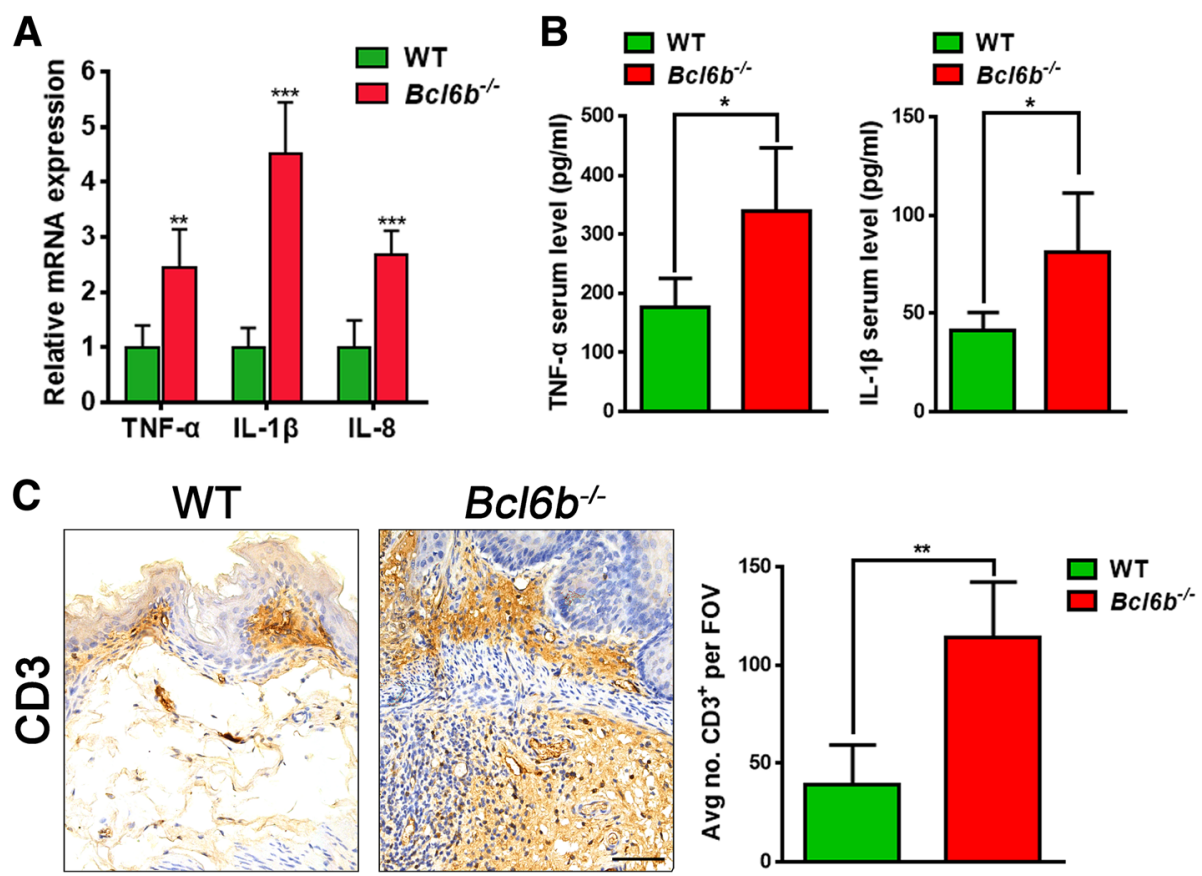

Fig. 3 Ablation of Bcl6b amplified inflammation upon BaP treatment. (a) qRT-PCR revealed TNF-a, IL-1 $\beta$ and IL-8 mRNA levels in Bap-induced

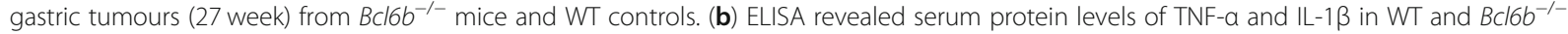
mice after intragastric administration of BaP (27 week). (c) Representative images and quantification of CD3-immunopositive cells in Bap-induced gastric tumours (27 week) from Bcl6 $6 b^{-1-}$ mice and WT controls. Scale bar, $50 \mu \mathrm{m}$. Data are presented as the mean $\pm \mathrm{SD} ; \mathrm{n}=5$ per group. ${ }^{*} P<0.05$; ${ }^{* *} P<0.01 ;{ }^{* * *} P<0.001$; unpaired two-tailed Student's $t$ tests

(Fig. 5c) and maximum tumour size (Fig. 5d) by greater than $70 \%$ in BaP-treated wildtype mice compared to saline controls, but only had a minor role in BaP-treated $\mathrm{Bcl}_{6 b^{-/-}}$mice. A $25 \%$ reduction in the tumour incidence following 5-Aza treatment was observed in the wildtype mouse GC model compared to saline controls, while a minor curative effect (12.5\% reduction) following 5-Aza treatment occurred in BaP-treated $\mathrm{Bcl}_{6} b^{-1-}$ mice (Fig. 5e). Moreover, Ki67 immunostaining showed that compared to the $28 \%$ reduction in $\mathrm{Ki}-67$ labelling following 5-Aza treatment in BaP-treated $B c l 6 b^{-1-}$ mice, Ki-67 positive cells were decreased by $65 \%$ upon 5 -Aza treatment in $\mathrm{BaP}$-treated wildtype mice relative to saline controls (Fig. 5f). Finally, Kaplan-Meier survival curves showed that survival time was dramatically shorter in $\mathrm{Bcl}_{6} \mathrm{~b}^{-1-}$ mice upon $\mathrm{BaP}$ treatment compared to the wildtype mice (Fig. 6e). Strikingly, 5Aza treatment significantly lengthened the survival time of BaP-treated wildtype mice, however, no significant prolongation of survival time following 5-Aza treatment was observed in the BaP-treated $B c l 6 b^{-1-}$ group (Fig. 6e). Taken together, these results demonstrated that 5-Aza effectively prevented BaP-induced gastric tumour development in a Bcl6b-dependent manner.
BCL6B downregulation combined with a severe inflammatory response correlates with poor survival in GC patients

To strengthen our main conclusion and further clarify the clinical significance of BCL6B and inflammation in $\mathrm{GC}$, cDNA microarrays from $45 \mathrm{GC}$ patients were first used to investigate the mRNA expression pattern of BCL6B and inflammatory cytokines. Notably, correlation analyses revealed strong inverse correlations between the overall expression levels of BCL6B and the inflammatory cytokines TNF $\alpha$ (Fig. 6a), IL-1 $\beta$ (Fig. 6b), and IL8 (Fig. 6c) in the 45 GC patient cohort. Next, we performed immunohistochemical staining of BCL6B and CD3 on GC tissue microarrays containing 186 GC specimens that had long-term clinical follow-up records. As the typical images show in Fig. 6d, all tumours presenting with greater than $5 \%$ positive staining of cells over the threshold were defined as BCL6B or CD3 positive. Subsequent Kaplan-Meier survival analysis showed that the GC tissue expression levels of BCL6B protein were inversely correlated with the 5-year survival rate of GC patients. BCL6B-negative GC patients had a median survival time of 56.5 months compared to BCL6B-positive GC patients who had a median survival time of 20.0 months (Fig. 6d), which is consistent with previous reports $[18,19]$ and our own survival results in mice as 


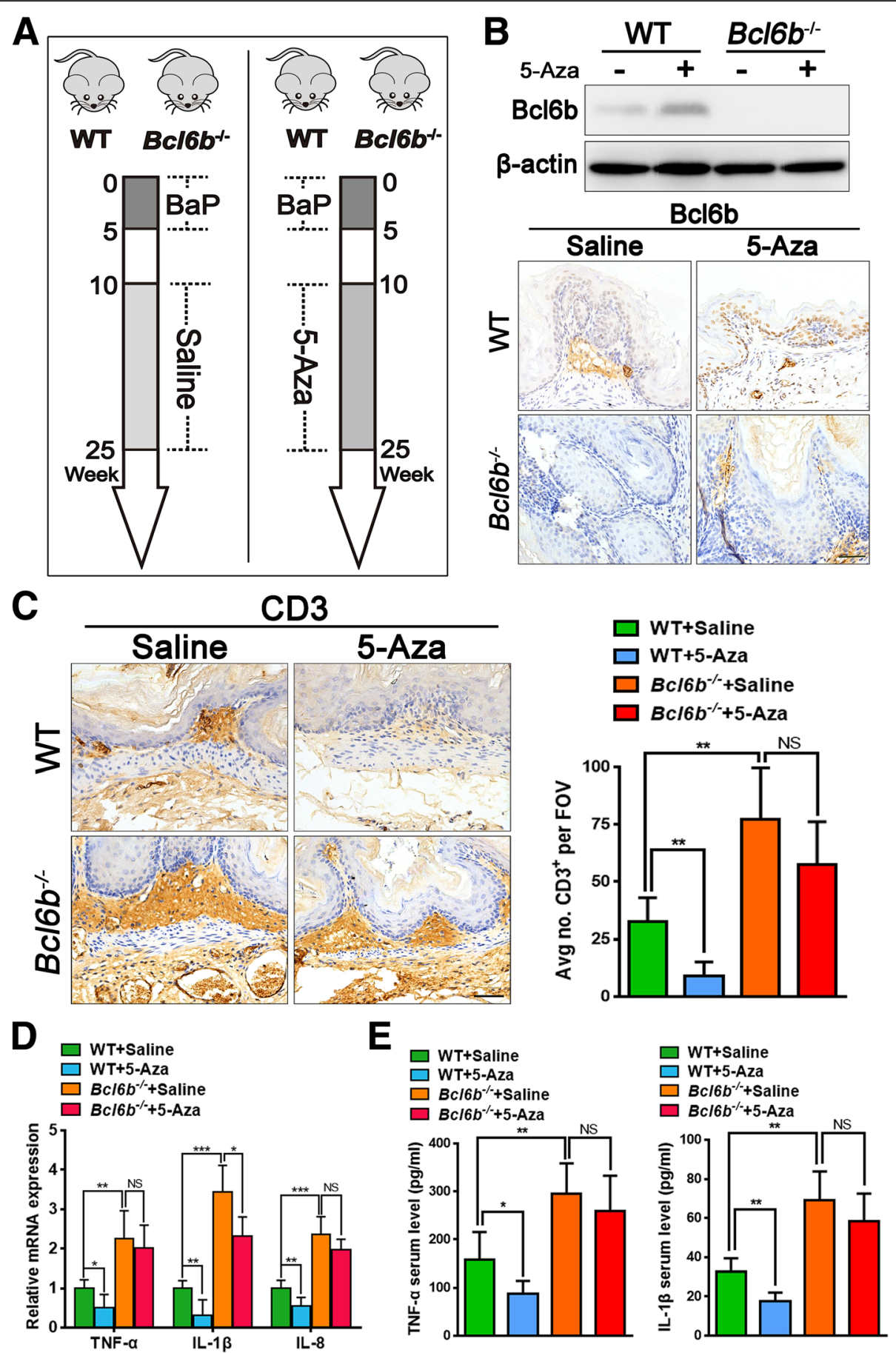

Fig. 4 5-Aza re-activated Bcl6b and inhibited inflammatory responses. (a) WT and $B c l 6 b^{-1-}$ mice were given Bap for gastric cancer induction during weeks 10-25 of treatment with or without the demethylation drug 5-Aza at a dose of $0.5 \mathrm{mg} / \mathrm{kg}$ for 15 consecutive weeks. (b) Representative images showing immunostaining and Western blotting of Bcl6b expression in Bap-induced gastric tumours (25 week) from $B c 16 b^{-1}$ mice and WT controls with or without 5-Aza treatment. Scale bar, $50 \mu \mathrm{m}$. (c) Representative images and quantification of CD3immunopositive cells in Bap-induced gastric tumours (25 week) from Bcl6b ${ }^{-1-}$ mice and WT controls with or without 5-Aza treatment. Scale bar, $50 \mu \mathrm{m}$. (d) qRT-PCR revealed TNF-a, IL-1 $\beta$ and IL-8 mRNA levels from stomachs harbouring BaP-induced tumours ( 25 week) from $B c 16 b^{-1-}$ mice and WT controls with or without 5-Aza treatment. (e) ELISA revealed serum protein levels of TNF- $\alpha$ and IL-1 $\beta$ in WT and Bcl6b $b^{-1-}$ mice after intragastric administration of $\mathrm{BaP}\left(25\right.$ week) with or without 5-Aza treatment. Data are presented as the mean $\pm S D ; n=5$ per group. ${ }^{*} P<0.05$; ${ }^{*} P<0.01 ;{ }^{* *} P<0.001 ;$ NS, not significant; unpaired two-tailed Student's $t$ tests 

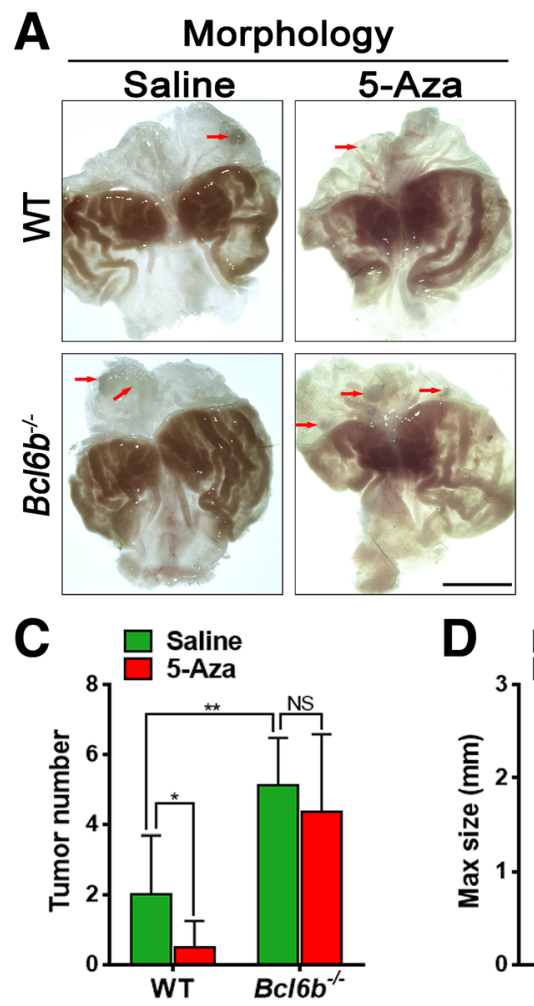

B
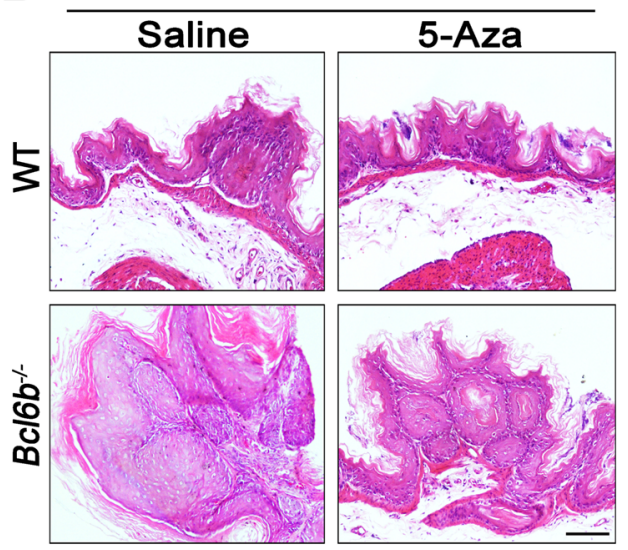

D $\square$ Saline
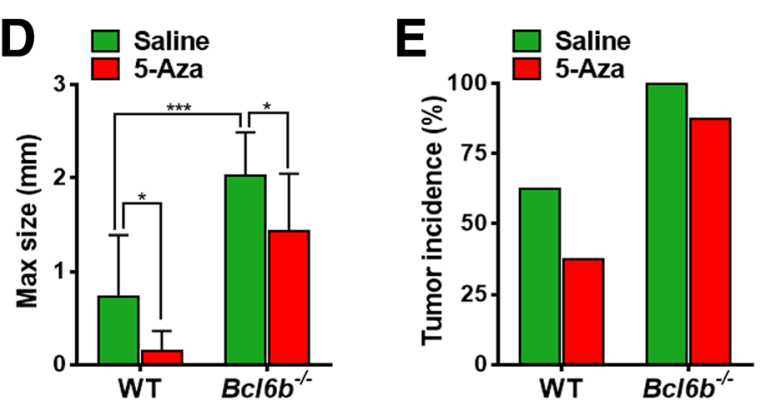
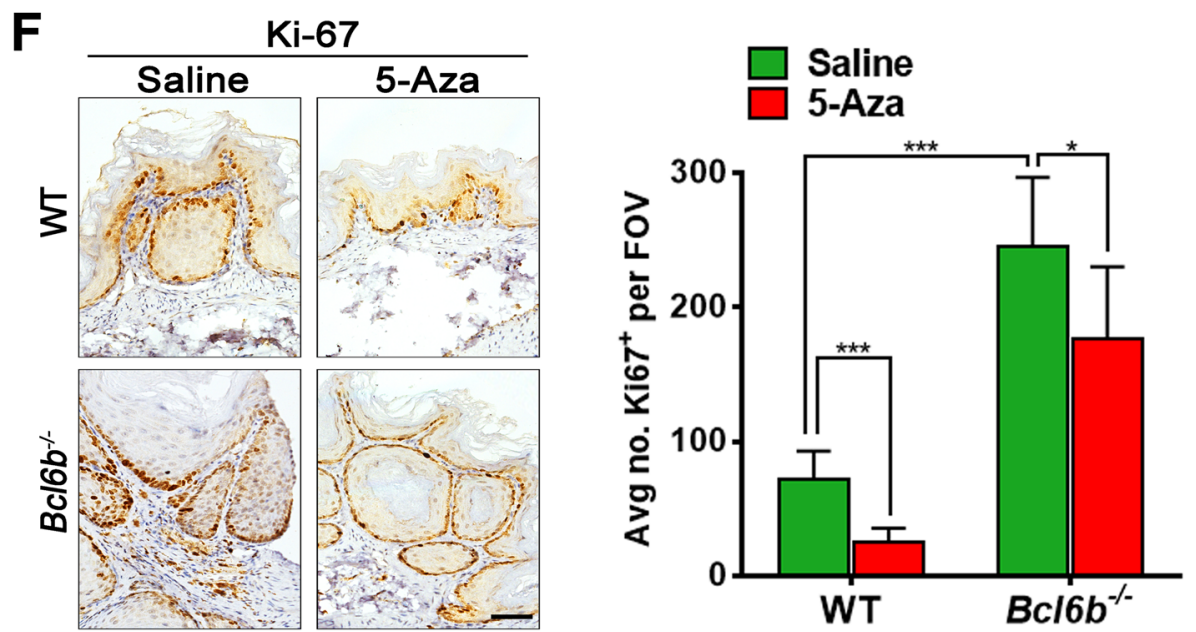

Fig. 5 5-Aza prevented BaP-induced gastric tumour development in a Bcl6b-dependent manner. (a, b) Representative images showing gross morphology (Scale bar, $5 \mathrm{~mm})(\mathbf{a})$ and H\&E staining (Scale bar, $100 \mu \mathrm{m})(\mathbf{b})$ of stomachs harbouring BaP-induced tumours ( 25 week) from Bcl6b ${ }^{-1}$ mice and WT controls with or without 5-Aza treatment. The gastric tumour granules were indicated by red arrows. (c-e) Tumour number (c), maximal size (d), and tumour incidence (e) in stomachs from WT and Bcl6b $b^{-1-}$ mice after intragastric administration of BaP (25 week) with or without 5-Aza treatment. (f) Representative images and quantification of Ki-67-immunopositive cells in Bap-induced gastric tumours (25 week) from $\mathrm{BCl}_{6 b^{-/-}}$mice and WT controls with or without 5-Aza treatment. Scale bar, $50 \mu \mathrm{m}$. Data are presented as the mean $\pm \mathrm{SD} ; n=8$ per group. ${ }^{*} P<0.05 ;{ }^{*} P<0.01 ;{ }^{* * *} P<0.001$; NS, not significant; unpaired two-tailed Student's $t$ tests

shown in Fig. 6e. Remarkably, IHC analysis showed that among BCL6B-negative GC patients, those with CD3positive expression exhibited the poorest survival (median survival time $=15.0$ months), whereas BCL6Bnegative GC patients with CD3-negative expression showed marginally different survival with a median survival time of 48.5 months (Fig. 6d). Taken together, the above results provide evidence that BCL6B is significantly negatively related to the degree of inflammation in GC and that negative BCL6B expression and a severe inflammatory response contribute jointly to the poor survival of GC patients. 

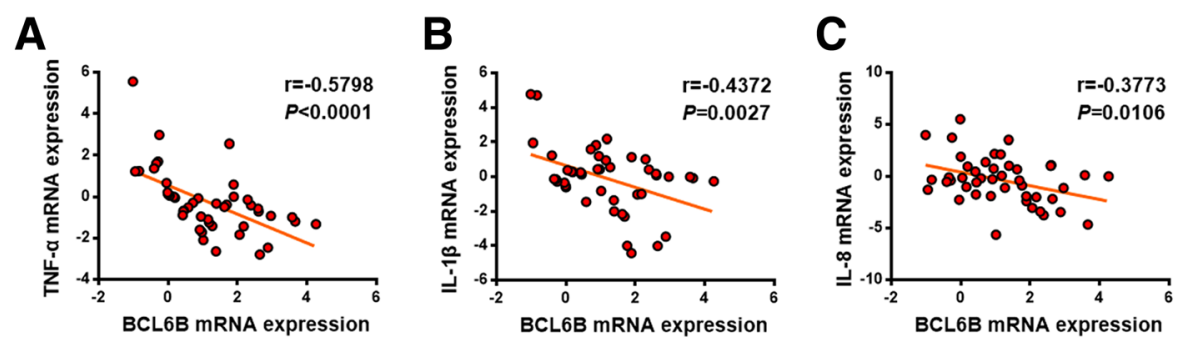

D

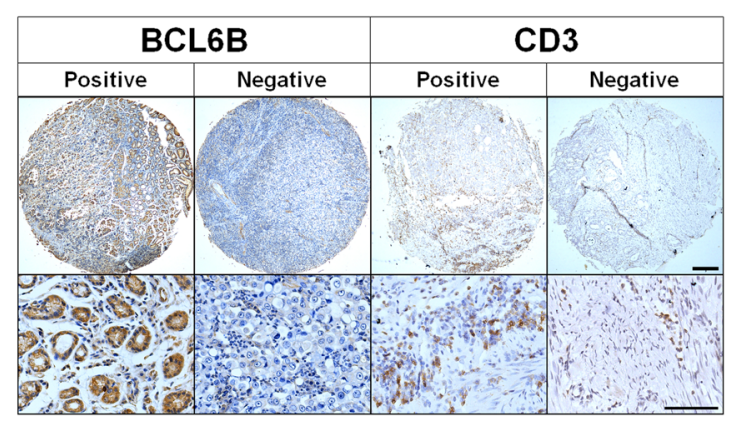

$\mathbf{E}$
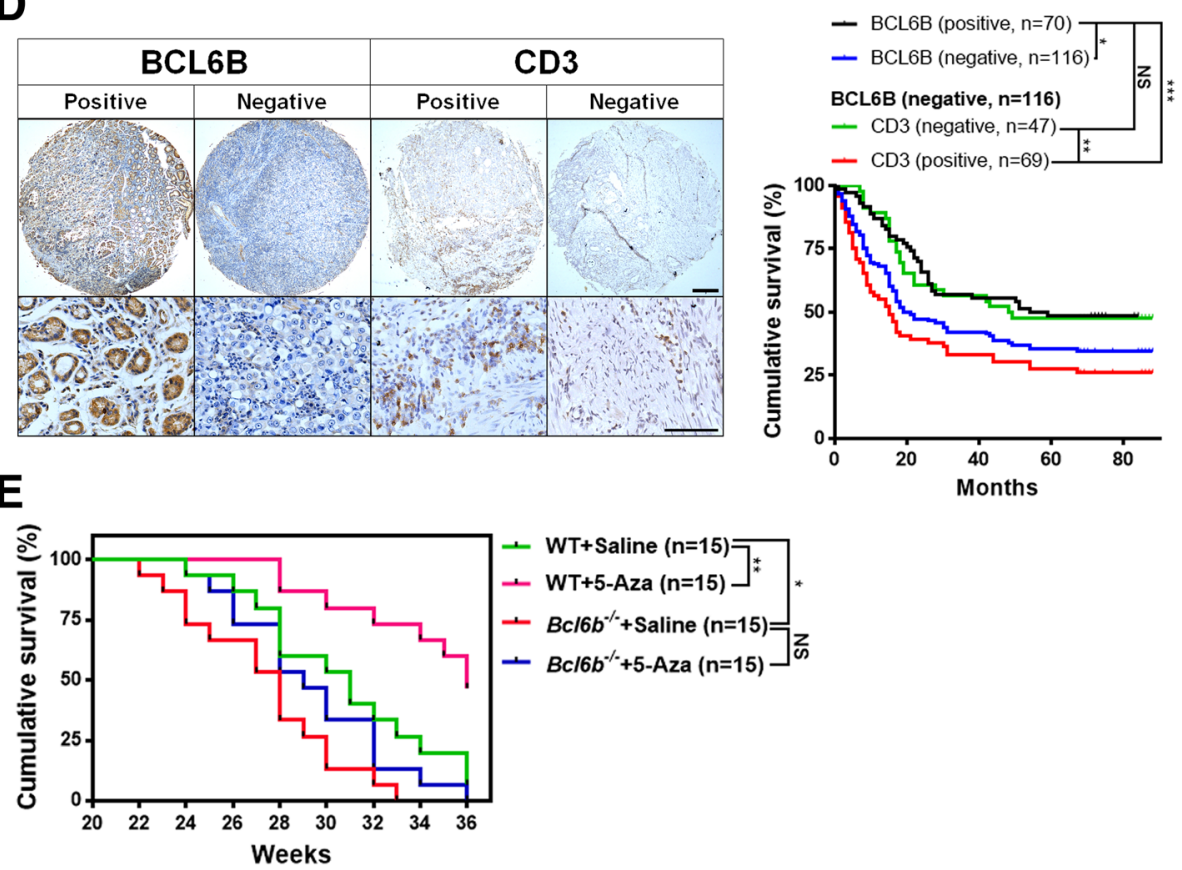

Fig. 6 BCL6B was associated with inflammation and survival in GC patients and mice. (a-c) Negative correlations between BCL6B and TNF-a (a), IL-1 $\beta$ (B) and IL-8 (c) mRNA levels in human gastric cancer tissues were measured using Pearson's correlation test ( $r$ and $P$ values are shown in the graphs, $n=45$ ). (d) Representative immunostaining of BCL6B and CD3 in human gastric cancer tissue microarrays. Scale bar, $100 \mu m$ (top) and 20 mm (bottom). Kaplan-Meier survival curves from overall gastric cancer patients based on BCL6B protein expression and BCL6B-negative gastric cancer patients based on CD3 protein expression. Survival analysis was performed using a log-rank test. (e) Kaplan-Meier survival curves of WT and $\mathrm{BCl}_{\mathrm{C}} \mathrm{b}^{-1-}$ mice after intragastric administration of BaP to induce gastric cancer with or without 5-Aza treatment. Survival analysis was performed using a log-rank test. ${ }^{*} P<0.05 ;{ }^{*} P<0.01 ;{ }^{* *} P<0.001$; NS, not significant

\section{Discussion}

In this study, we used Bcl6b-deficient mice and 5-Azatreated mice to evaluate the role of $\mathrm{Bcl} 6 \mathrm{~b}$ in $\mathrm{BaP}$ induced gastric inflammation and GC development. This study provided compelling evidence that Bcl6b functions as a tumour suppressor to inhibit GC and suggested a novel inflammatory strategy to control GC. Previous studies have showed that inflammation is a hallmark of cancer and a pro-tumourigenic factor $[25,26]$. Furthermore, gastritis stage is used to quantify GC risk [27] and GC patients with a severe inflammatory response exhibit poor survival [28]. Thus, effective inflammation control has been recognized as both a preventative and treatment strategy for GC [29-31]. In the present study, we found that Bcl6b was gradually downregulated by its own promoter hypermethylation in parallel to an increased inflammatory response during the progression of $\mathrm{BaP}$-induced gastric carcinogenesis in mice. Moreover, knockout of $B c l 6 b$ amplified the inflammatory response and aggravated gastric tumourigenesis in mice upon $\mathrm{BaP}$ treatment. Re-activation of Bcl6b by the demethylation drug 5-Aza could impede inflammatory amplification and Bap-induced GC development, further prolonging the survival time in wildtype mice, whereas no notable curative effect was observed in $\mathrm{Bcl}_{6} \mathrm{~b}^{-/-}$mice with 5-Aza treatment. Analyses of clinical GC specimens showed that negative BCL6B expression together with a severe inflammatory response resulted in the poorest survival in GC patients. We therefore conclude that Bcl6b plays a crucial role in regulating inflammation-associated GC initiation and development in vivo and that 5-Aza can be used as an anti-tumour compound through re-activation of Bcl6b. 
Given that the inflammatory response has been reported to modulate $\mathrm{GC}$ development [32-34] and that $\mathrm{BaP}$ is a carcinogen that is most likely ingested during daily human life $[35,36]$, BaP can induce cancerous lesions in the human stomach and result in gastric carcinogenesis by promoting a pro-inflammatory phenotype [5, 37-39]. In addition, feeding of mice with $\mathrm{BaP}$ has been an extensively applied method for the establishment of mouse GC models [40, 41]. Thus, BaPinduced mouse GC is therefore an ideal model for the study of inflammation-associated GC. Consistent with our observation in our mouse GC model induced by $\mathrm{BaP}$ gavage, inflammation gradually increased during gastric carcinogenesis with a corresponding decreasing trend for Bcl6b. In human GC samples, Bcl6b expression exhibited a negative correlation with inflammatory cytokines. Based on the previous report that BCL6B is an independent predictor of poor outcome in patients with GC [19]. Our study further indicates that combination of BCL6B expression and inflammatory response may improve the prognosis accuracy in GC patient survival. Moreover, our results showed that Bcl6b inhibition remarkably aggravated gastric inflammation in BaP-induced mice. These findings indicate that BCL6B functions as a key inflammatory regulator in the progression of gastric oncogenesis in vivo. However, the precise regulatory mechanisms underlying the relationship between BCL6B and inflammatory cytokines has not yet been elucidated. Several previous studies revealed that BCL6B interacts with the Notch, STAT, p53 and PI3K/AKT signalling pathways $[15,16,21,22]$, which may be involved in the regulation of the inflammatory response in cancer cells. Future studies should verify which core signalling pathway BCL6B depends on for the regulation of the inflammatory response in inflammation-associated GC development.

From a clinical point of view, both BCL6B and gastric inflammation should be precisely regulated within a suitable range to control normal development and homeostasis. However, this balance may be disrupted during carcinogenesis. It has been reported that BCL6B is silenced via its own promoter hypermethylation in GC [19], which is consistent with our observation that the methylated levels of the Bcl $6 b$ promoter were gradually up-regulated during the process of gastric tumourigenesis by $\mathrm{BaP}$ induction. In our study, which aimed to investigate an existing clinical drug to target Bcl6b in inflammation-associated GC in vivo. We used the DNA demethylation drug 2'-deoxy-5-azacytidine (5-Aza), which has been applied for the clinical treatment of multiple haematologic malignancies and solid tumours $[42,43]$. Our results revealed that 5-Aza treatment effectively restored Bcl6b expression and dramatically blocked gastric inflammation and GC development. In contrast, 5-Aza treatment had a weak therapeutic effect on BaP-induced GC in $\mathrm{Bcl} \mathrm{bb}^{-/-}$mice. This study, along with another complementary reports $[44,45]$ confirmed that a specific panel of candidate genes (BCL6B, GDF1, FBP1, BNIP3, CDX1, CHFR, MGMT, MLH1, etc.) are aberrantly activated or silenced by methylation in stomach tumours. Our results in $B c l 6 b^{-1-}$ mice suggest that the therapeutic effect of 5-Aza on BaP-induced GC depends on the activation of Bcl6b, which highlights the key role of $B C L 6 B$ methylation in the occurrence and development of GC. In clinical trials, the demethylation drug 5Aza, which broadly targets DNA, showed high toxicity [46-48]. Thus, a novel anti-GC drug that can selectively target BCL6B with low toxicity is urgently needed.

\section{Conclusions}

In summary, our study showed that BCL6B acts as a dominant tumour suppressor in GC and plays a crucial role in inflammatory response control in vivo. Manipulating the expression of BCL6B may provide a new entry point for $\mathrm{GC}$ treatment and regenerative medicine.

\section{Additional files}

Additional file 1: Figure S1. Representative images showing immunostaining of Pan-Cytokeratin expression (Scale bar, $50 \mu \mathrm{m}$ ) from stomachs harbouring BaP-induced tumours (27 week) from Bcl6b $b^{-/}$mice and WT controls (PDF $617 \mathrm{~kb}$ )

Additional file 2: Figure S2. Representative images showing PanCytokeratin immunostaining (Scale bar, $50 \mu \mathrm{m}$ ) of stomachs harbouring BaP-induced tumours (25 week) from $\mathrm{BCl}_{6 b^{-/}}$mice and WT controls with or without 5-Aza treatment (PDF $750 \mathrm{~kb}$ )

\section{Abbreviations \\ 5-Aza: 5-Aza-2'-deoxycytidinel; BaP: Benzo[a]pyrene; BCL6: B cell CLL/ lymphoma 6; BCL6B: B cell CLL/lymphoma 6 member B; BGS: Bisulphite genomic sequencing; ELISA: Enzyme-linked immunosorbent assay; GC: Gastric cancer; H\&E staining: Haematoxylin and eosin staining; IHC: Immunohistochemistry; IL-1 $\beta$ : Interleukin 1 beta; IL-6: Interleukin 6; IL- 8: Interleukin 8; mRNA: messenger RNA; qPCR: quantitative PCR; TNF- a: Tumour necrosis factor alpha; WT: Wildtype}

\section{Acknowledgements}

Not applicable.

\section{Authors' contributions}

Study concept and design: WYC, LW \& QCL; acquisition and analysis of data: WYC, LYL, LY, LW \& JC; drafting of the manuscript: WYC, LYL \& QCL; statistical analysis: QZ, YYX \& MLC; obtained funding: WYC, QCL \& GDY; technical or material support: GDY, MLC \& LW. All authors read and approved the final manuscript.

\section{Funding}

This work was supported by grants from the National Natural Science Foundation of China (grant number 81602148 to Wang-Yu Cai; grant number 81872422, 81672871 to Qi-Cong Luo; grant number 81602563, 81871977 to Guo-Dong Ye); the Natural Science Foundation of Fujian Province (grant number 2015 J01523 to Wang-Yu Cai); and the Science and Technology Projects of Xiamen City (grant number $3502 Z 20154025$ to Wang-Yu Cai). 


\section{Availability of data and materials}

All data generated or analysed during this study are included in this published article

\section{Ethics approval and consent to participate}

The studies were conducted in accordance with the international ethical guidelines for biomedical research involving human subjects (CIOMS), and the research protocols were approved by the clinical research ethics Committee of Zhongshan Hospital of Xiamen University. Written informed consents were obtained from the participants before sampling.

\section{Consent for publication}

Not applicable

\section{Competing interests}

The authors declare that they have no competing interests.

\section{Author details}

'Department of Gastrointestinal Surgery, Zhongshan Hospital, Xiamen University, No. 201-209 Hubinnan Road, Xiamen 361004, Fujian Province, China. ${ }^{2}$ Department of Oncology, Zhongshan Hospital, Xiamen University, No. 201-209 Hubinnan Road, Xiamen 361004, Fujian Province, China. ${ }^{3}$ Laboratory of Xiamen Cancer Hospital, The First Affiliated Hospital of Xiamen University, No.55 Zhenhai Road, Xiamen 361003, Fujian Province, China. ${ }^{4}$ Institute of Gastrointestinal Oncology, School of Medicine, Xiamen University, Xiamen, Fujian, China. ${ }^{5}$ Department of Pathology, School of Medicine, Jinan University, Guangzhou, Guangdong, China. ${ }^{6}$ Xiamen Lifelnt Technology Co., Ltd., Xiamen, Fujian, China.

Received: 20 February 2019 Accepted: 2 July 2019

Published online: 09 July 2019

\section{References}

1. Bray F, Ferlay J, Soerjomataram I, Siegel RL, Torre LA, Jemal A. Global cancer statistics 2018: GLOBOCAN estimates of incidence and mortality worldwide for 36 cancers in 185 countries. CA Cancer J Clin. 2018;68(6):394-424.

2. Dinis-Ribeiro M, Areia M, de Vries AC, Marcos-Pinto R, Monteiro-Soares M, O'Connor A, Pereira C, Pimentel-Nunes P, Correia R, Ensari A, et al. Management of precancerous conditions and lesions in the stomach (MAPS): guideline from the European Society of Gastrointestinal Endoscopy (ESGE), European helicobacter study group (EHSG), European Society of Pathology (ESP), and the Sociedade Portuguesa de Endoscopia Digestiva (SPED). Endoscopy. 2012:44:74-94.

3. Hollstein PE, Shaw RJ. Inflamed T cells and stroma drive gut tumors. Science. 2018:361:332-3.

4. Bornschein J, Selgrad M, Warnecke M, Kuester D, Wex T, Malfertheiner P. H. Pylori infection is a key risk factor for proximal gastric cancer. Dig Dis Sci. 2010;55:3124-31.

5. Labib S, Guo CH, Williams A, Yauk CL, White PA, Halappanavar S. Toxicogenomic outcomes predictive of forestomach carcinogenesis following exposure to benzo(a)pyrene: relevance to human cancer risk. Toxicol Appl Pharmacol. 2013;273:269-80

6. Jiang Y, Qi X, Liu X, Zhang J, Ji J, Zhu Z, Ren J, Yu Y. Fbxw7 haploinsufficiency loses its protection against DNA damage and accelerates MNU-induced gastric carcinogenesis. Oncotarget. 2017;8:33444-56.

7. Tafreshi M, Guan J, Gorrell RJ, Chew N, Xin Y, Deswaerte V, Rohde M, Daly RJ, Peek RM Jr, Jenkins BJ, et al. Helicobacter pylori type IV secretion system and its Adhesin subunit, CagL, mediate potent inflammatory responses in primary human endothelial cells. Front Cell Infect Microbiol. 2018;8:22.

8. Crabtree JE. Gastric mucosal inflammatory responses to helicobacter pylori. Aliment Pharmacol Ther. 1996;10(Suppl 1):29-37.

9. Tsai HF, Hsu PN. Modulation of tumor necrosis factor-related apoptosisinducing ligand (TRAIL)-mediated apoptosis by helicobacter pylori in immune pathogenesis of gastric mucosal damage. J Microbiol Immunol Infect. 2017;50:4-9.

10. Zhang Y, Liu Y, Song R, Zhang L, Su Z, Li Y, Chen R, Shi N, Zhao X, Du S, et al. Validating traditional Chinese syndrome features in varied stages of chronic gastritis malignant transformation: study protocol for a crosssectional study. BMJ Open. 2018;8:e020939.
11. Sakashita C, Fukuda T, Okabe S, Kobayashi H, Hirosawa S, Tokuhisa T, Miyasaka N, Miura O, Miki T. Cloning and characterization of the human BAZF gene, a homologue of the BCL6 oncogene. Biochem Biophys Res Commun. 2002:291:567-73.

12. Ishii K, Kanatsu-Shinohara M, Toyokuni S, Shinohara T. FGF2 mediates mouse spermatogonial stem cell self-renewal via upregulation of Etv5 and Bcl6b through MAP2K1 activation. Development. 2012;139:1734-43.

13. Okabe S, Fukuda T, Ishibashi K, Kojima S, Okada S, Hatano M, Ebara M, Saisho H, Tokuhisa T. BAZF, a novel Bcl6 homolog, functions as a transcriptional repressor. Mol Cell Biol. 1998;18:4235-44.

14. Takenaga M, Hatano M, Takamori M, Yamashita Y, Okada S, Kuroda Y, Tokuhisa T. Bcl6-dependent transcriptional repression by BAZF. Biochem Biophys Res Commun. 2003;303:600-8.

15. Gu Y, Li A, Sun H, Li X, Zha H, Zhao J, Xie J, Zeng Z, Zhou L. BCL6B suppresses proliferation and migration of colorectal carcinoma cells through inhibition of the PIBK/AKT signaling pathway. Int J Mol Med. 2018:41:2660-8

16. Li X, Yu J, Brock MV, Tao Q, Herman JG, Liang P, Guo MZ. Epigenetic silencing of BCL6B inactivates p53 signaling and causes human hepatocellular carcinoma cell resist to 5-FU. Oncotarget. 2015;6:11547-60.

17. Wang J, Dong L, Xu L, Chu ES, Chen Y, Shen J, Li X, Wong CC, Sung $J$ J, Yu J. B cell CLL/lymphoma 6 member B inhibits hepatocellular carcinoma metastases in vitro and in mice. Cancer Lett. 2014;355:192-200

18. Deng J, Liang H, Dong Q, Hou Y, Xie X, Yu J, Fan D, Hao X. The survival decrease in gastric cancer is associated with the methylation of B-cell CLL/lymphoma 6 member B promoter. Open Biol. 2014;4.

19. Xu L, Li X, Chu ES, Zhao G, Go MY, Tao Q, Jin H, Zeng Z, Sung JJ, Yu J. Epigenetic inactivation of BCL6B, a novel functional tumour suppressor for gastric cancer, is associated with poor survival. Gut. 2012;61:977-85.

20. Yang Q, Gao J, Xu L, Zeng Z, Sung JJ, Yu J. Promoter hypermethylation of $\mathrm{BCL6B}$ gene is a potential plasma DNA biomarker for gastric cancer. Biomarkers. 2013;18:721-5.

21. Ohnuki $H$, Inoue $H$, Takemori $N$, Nakayama H, Sakaue T, Fukuda S, Miwa D, Nishiwaki E, Hatano M, Tokuhisa T, et al. BAZF, a novel component of cullin3-based E3 ligase complex, mediates VEGFR and notch cross-signaling in angiogenesis. Blood. 2012;119:2688-98.

22. Hartatik T, Okada S, Okabe S, Arima M, Hatano M, Tokuhisa T. Binding of BAZF and Bc16 to STAT6-binding DNA sequences. Biochem Biophys Res Commun. 2001;284:26-32.

23. Wang W, Huang $P$, Wu P, Kong R, Xu J, Zhang L, Yang Q, Xie Q, Zhang L, Zhou $X$, et al. BCL6B expression in hepatocellular carcinoma and its efficacy in the inhibition of liver damage and fibrogenesis. Oncotarget. 2015;6:20252-65.

24. Boccellato F, Woelffling S, Imai-Matsushima A, Sanchez G, Goosmann C, Schmid M, Berger H, Morey P, Denecke C, Ordemann J, et al. Polarised epithelial monolayers of the gastric mucosa reveal insights into mucosal homeostasis and defence against infection. Gut. 2019;68:400-13.

25. Grivennikov SI, Greten FR, Karin M. Immunity, inflammation, and cancer. Cell. 2010;140:883-99.

26. Hanahan D, Weinberg RA. Hallmarks of cancer: the next generation. Cell. 2011;144:646-74.

27. Rugge M, Genta RM, Fassan M, Valentini E, Coati I, Guzzinati S, Savarino E, Zorzi M, Farinati F, Malfertheiner P. OLGA gastritis staging for the prediction of gastric Cancer risk: a long-term follow-up study of 7436 patients. Am J Gastroenterol. 2018.

28. Wang K, Diao F, Ye Z, Zhang X, Zhai E, Ren H, Li T, Wu H, He Y, Cai S, et al. Prognostic value of systemic immune-inflammation index in patients with gastric cancer. Chin J Cancer. 2017:36:75.

29. Rugge M, Genta RM, Di Mario F, El-Omar EM, El-Serag HB, Fassan M, Hunt RH, Kuipers EJ, Malfertheiner P, Sugano K, et al. Gastric Cancer as preventable disease. Clin Gastroenterol Hepatol. 2017:15:1833-43.

30. Thun MJ, Jacobs EJ, Patrono C. The role of aspirin in cancer prevention. Nat Rev Clin Oncol. 2012;9:259-67.

31. Wang F, Meng W, Wang B, Qiao L. Helicobacter pylori-induced gastric inflammation and gastric cancer. Cancer Lett. 2014;345:196-202.

32. Kodama M, Murakami K, Nishizono A, Fujioka T. Animal models for the study of helicobacter-induced gastric carcinoma. J Infect Chemother. 2004;10:316-25.

33. Park YH, Kim N. Review of atrophic gastritis and intestinal metaplasia as a premalignant lesion of gastric cancer. J Cancer Prev. 2015;20:25-40. 
34. Agreus L, Kuipers EJ, Kupcinskas L, Malfertheiner P, Di Mario F, Leja M, Mahachai V, Yaron N, van Oijen M, Perez Perez G, et al. Rationale in diagnosis and screening of atrophic gastritis with stomach-specific plasma biomarkers. Scand J Gastroenterol. 2012:47:136-47.

35. Baan R, Grosse Y, Straif K, Secretan B, El Ghissassi F, Bouvard V, BenbrahimTallaa L, Guha N, Freeman C, Galichet L, et al. A review of human carcinogens--part F: chemical agents and related occupations. Lancet Oncol. 2009;10:1143-4.

36. Hattemer-Frey HA, Travis CC. Benzo-a-pyrene: environmental partitioning and human exposure. Toxicol Ind Health. 1991;7:141-57.

37. Bodduluru LN, Kasala ER, Madhana RM, Barua CC, Hussain MI, Haloi P, Borah P. Naringenin ameliorates inflammation and cell proliferation in benzo(a)pyrene induced pulmonary carcinogenesis by modulating CYP1A1, NFkappaB and PCNA expression. Int Immunopharmacol. 2016;30:102-10.

38. Fueldner C, Kohlschmidt J, Riemschneider S, Schulze F, Zoldan K, Esser C, Hauschildt S, Lehmann J. Benzo(a)pyrene attenuates the patternrecognition-receptor induced proinflammatory phenotype of murine macrophages by inducing IL-10 expression in an aryl hydrocarbon receptordependent manner. Toxicology. 2018;409:80-90.

39. Malik DE, David RM, Gooderham NJ. Mechanistic evidence that benzo[a]pyrene promotes an inflammatory microenvironment that drives the metastatic potential of human mammary cells. Arch Toxicol. 2018;92:3223-39

40. Wang Q, Xue Y. Characterization of solid tumors induced by polycyclic aromatic hydrocarbons in mice. Med Sci Monit Basic Res. 2015;21:81-5.

41. Culp SJ, Gaylor DW, Sheldon WG, Goldstein LS, Beland FA. A comparison of the tumors induced by coal tar and benzo[a]pyrene in a 2-year bioassay. Carcinogenesis. 1998;19:117-24.

42. Cowan LA, Talwar S, Yang AS. Will DNA methylation inhibitors work in solid tumors? A review of the clinical experience with azacitidine and decitabine in solid tumors. Epigenomics. 2010;2:71-86.

43. Mack GS. To selectivity and beyond. Nat Biotechnol. 2010;28:1259-66.

44. Yang W, Mok MT, Li MS, Kang W, Wang H, Chan AW, Chou JL, Chen J, Ng EK, To KF, et al. Epigenetic silencing of GDF1 disrupts SMAD signaling to reinforce gastric cancer development. Oncogene. 2016;35:2133-44.

45. Wang K, Yuen ST, Xu J, Lee SP, Yan HH, Shi ST, Siu HC, Deng S, Chu KM, Law $\mathrm{S}$, et al. Whole-genome sequencing and comprehensive molecular profiling identify new driver mutations in gastric cancer. Nat Genet. 2014;46:573-82

46. Agrawal K, Das V, Vyas P, Hajduch M. Nucleosidic DNA demethylating epigenetic drugs - a comprehensive review from discovery to clinic. Pharmacol Ther. 2018;188:45-79.

47. Lubbert M, Suciu S, Baila L, Ruter BH, Platzbecker U, Giagounidis A, Selleslag D, Labar B, Germing U, Salih HR, et al. Low-dose decitabine versus best supportive care in elderly patients with intermediate- or high-risk myelodysplastic syndrome (MDS) ineligible for intensive chemotherapy: final results of the randomized phase III study of the European Organisation for Research and Treatment of Cancer leukemia group and the German MDS study group. J Clin Oncol. 2011;29:1987-96.

48. Kantarjian H, Oki Y, Garcia-Manero G, Huang X, O'Brien S, Cortes J, Faderl S, Bueso-Ramos C, Ravandi F, Estrov Z, et al. Results of a randomized study of 3 schedules of low-dose decitabine in higher-risk myelodysplastic syndrome and chronic myelomonocytic leukemia. Blood. 2007;109:52-7.

\section{Publisher's Note}

Springer Nature remains neutral with regard to jurisdictional claims in published maps and institutional affiliations.

Ready to submit your research? Choose BMC and benefit from:
- fast, convenient online submission
- thorough peer review by experienced researchers in your field
- rapid publication on acceptance
- support for research data, including large and complex data types
- gold Open Access which fosters wider collaboration and increased citations
- maximum visibility for your research: over 100M website views per year
At BMC, research is always in progress.
Learn more biomedcentral.com/submissions

